\title{
On the Supplement of the Great Chinese Dictionary
}

\author{
Xiao Jiugen ${ }^{1}$, Xiong Lingjun ${ }^{2}$ \\ ${ }^{1}$ College of Liberal Arts, Jiangxi Normal University, Nanchang, Jiangxi, China \\ ${ }^{2}$ College of Media, Nanchang Institute of Technology, Nanchang, Jiangxi, China
}

\section{Email address:}

jxsdxjg666666@sina.com (Xiao Jiugen),15568659@qq.com (Xiong Lingjun)

\section{To cite this article:}

Xiao Jiugen, Xiong Lingjun. On the Supplement of the Great Chinese Dictionary. Education Journal. Vol. 4, No. 5, 2015 , pp. $320-324$. doi: $10.11648 /$ j.edu. 20150405.32

\begin{abstract}
Chinese Dictionary is not only a major reference book in China at present, but also a monument in the history of authoritative Chinese dictionary compilation. However, due to various factors, there are inevitably some omissions or errors in the dictionary, for example, some commonly used words are ignored, and some documentary evidences are provided too late, some words' meanings are incomplete and misinterpreted. This paper mainly presents some words entry, documentary evidence and meaning being worthwhile to revise and supplement.
\end{abstract}

Keywords: Chinese Dictionary, Revise, Supplementary, Words Entry, Documentary Evidence, Meaning

\section{关于《汉语大词典》修订商补问题}

肖九根 ${ }^{1}$, 熊玲君 ${ }^{2}$

${ }^{1}$ 江西师范大学文学院, 南昌, 江西, 中国

南昌理工学院传播学院, 南昌, 江西, 中国

\section{邮箱}

jxsdxjg666666@sina.com（肖九根），15568659@qq. com（熊玲君）

摘要: 《汉语大词典》不仅是中国目前一部最具权威性的大型工具书, 还是中国辞书编纂史上的一座丰碑。不过, 由 于各种因素的制约, 这部辞书难免也存在一些疏漏甚至忡误, 如有些常用词失收, 有些书证付成或偏晚, 有些义项未 立或不全, 有些词义误释等问题。本文主要提出部分值得商补的词条、书证、义项, 以俟修订时能择而补之。

关键词: 《汉语大词典》, 修订, 商补, 词条, 书证, 义项

\section{1. 引言}

《汉语大词典》是中国一部最具权威性的大型语文 工具书。这部辞书凝聚着无数学者的智慧和心血, 其编 纂人数之多, 时间之久, 篇幅之大, 内容之全, 在中国 以手工制作为主的辞书编纂史上堪称是一个前所未有 的壮举, 也是中国辞书发展史上的一座伟大丰碑。这部 辞书以 “古今兼收, 源流并重” 的广博内容, “泽溉整 个学术界乃至文化界, 意义重大, 影响深远”。[1] (p10-15) 不过, 由于历史客观条件等因素的制约, 这
部词典如同其他辞书一样, 难免也存有这样或那样的疏 漏甚至多误。笔者时常检阅《汉语大词典》, 颇受教益; 与此同时, 也发现了不少值得商兑增补的地方。现不揣 浅陋, 冒昧地列举一些条目, 冀望为《汉语大词典》的 修订提供一些有益的参考, 如有不妥之处, 敬祈方家指 正。

下面主要谈三个方面的问题：一是商补一些常见 的词条, 二是商补一些词条中的例证, 三是商补一些 词条中的义项。由于篇幅所限, 每类仅举数例, 以资 说明。 


\section{2. 商补一些常见的词条}

有些词语十分常见, 不仅见于各类文献, 还往往用于 人们的日常口语中。这些普通常用的词语, 一般辞书都已 收录, 而最富权威的《汉语大词典》却失收了, 委实有些 遗憾。例如, 下面一些词语, 《汉语大词典》修订时可否 甚酶补入?

【磕破】“击物破碎”义。“磕”本谓“石头撞击声”。 《说文・石部》: “磕, 石声。” [2]（p623）《正字通・石 部》: “磕, 雨石相击声。” [3] 引申为 “敲击” 义。《一 切经音义》“相磕”条注: “今江南凡言打物破碎为磕破。” [4]（p1729）此 “碳破” 正是 “击物而破” 义, 属述补型 复合词。元・刘唐卿《蔡顺奉母》第二折：“（云）小生 对着神天, 将头也磕破了, 滴下来的泪珠儿, 可都成冰了。” 明 - 施耐庵《水吘传》第三 $\bigcirc$ 回: “那妇人才方从缸里扒 得出来, 头脸都吃磕破了。”

“磕破”为古江南方言。今方言区如赣语、江淮官话 等亦常把 “击碎物” 谓之 “磕破” 。清・桂馥《札朴》卷 九：“打物破曰磕破。”[5]（p392）显然，北方某些方 言也有其说, 如中原官话山东曲皁等地。《汉语大词典》 未收“磕破”一词。

【包满】意指 “隐瞒事实真相”。“包” 本谓 “裹着”。 《广雅・释诂四》: “包, 裹也。”[6]（p49）“裹着” 则人不知其详, 故有 “掩藏” 义。“瞒” 亦谓 “掩藏”、 “欺骗”义。《正字通・目部》: “瞒, 俗以匿情相欺为 瞒。” [3]复合结构 “包瞒” , 即 “隐瞒事实真相” 之谓。 清・韩庆邦《海上花列传》第一六回: “难末说勿如让俚 出来做做生意看, 倘忙碰着个好客人, 看俚命苦, 肯搭俚 包瞒仔该桩事体, 要救到七八条性命哚!”第四一回: “张 寿捉空央求淑人, 为之包瞒。”

方言区如吴语、赣语等, 习用其语。有些辞书已经收 入, 《汉语大词典》未见此条。

【门龙】指 “门椐” , 即门户上的横梁。《尔雅》: “楣之谓梁。” 郭璞注: “楣, 门户上横梁。” [7] ( p40) 清・郝懿行疏: “今登莱谓之门梁, 江浙谓之门龙。” [8] （p157）方言区吴语、赣语等, 还把 “门楣”谓之 “门龙”。 “门椐” 缘何称为 “门龙” 呢? 其理据是那架在门户上木 刻的横梁形似游龙, 人们认为它有驱邪纳祥的作用。过去, 不少乡间均有龙状门椐之刻雕, 工艺繁是精良, 颇具艺术 特色。《汉语大词典》未收此条。

【媞妋】 “媞” 本义 “审谛”。《说文・女部》: “媞, 谛也。”[2]（p824）段玉裁注: “谛者, 审也; 审者, 悉也。” [9]（p620）又 “替”, 义同 “媞”。《说文・女 部》: “替, 媞也。” [2]（p824）《集韵・支韵》: “替, 妇女审谛完。” [10（p9）因而，同义复合结构 “媞替” 亦谓 “审谛” 义, 即 “慎重或仔细考察”。《新方言・释 言》: “《说文》: “替, 媞也。居随切。” “媞, 谛也。 承旨切。' 今荆州谓女子言动审谛为 '媞' 。替读如居, 双声相转。”[11]

方言区如赣语、西南官话等, 今犹常言 “媞替”一语。 《汉语大词典》未收。

【懵营懂懂】营哩营懂】这是“懵懂”一词的“AABB”、 “A哩 $A B$ ” 叠加式。《大词典》收了 “懵懂” , 释之 “糊
涂; 迷糊”, 是也。《玉篇・ 心部》: “懵, 心迷也。” [12]《广韵・董韵》: “懵, 心乱皃。” [13] (p158) 又, 《集韵・东韵》: “買, 懵懵, 无知完。”[10]（p3）) 故 “懵懂” 亦即 “糊涂无知, 不明事理” 义。清 - 桂馥《札 朴》卷九：“疑惑曰懜懂。” [5]（p391）宋・葛长庚《贺 新郎・送赵师之江州》: “垂手入㢆长是醉, 醉则从教懵 懂。”元・谷子敬《城南柳》第一折： “这火凡夫都是些 懵懂之徒, 不识回仙元姓吕。”

“懵懂” 的重叠式 “AABB”, 古文献早有用例。元 - 纪 君祥《赵氏孤儿》第四折: “屠岸贾将我的孩儿十分见喜, 他岂知就里的事。只是一件, 连我这孩儿心下也还是懵懵 懂懂的。”明- 吴承恩《西游记》第二八回: “呆子懵懵 懂懂的, 托着针孟, 概着钉钯, 与沙僧径直回来。”

方言区如吴语、赣语、湘语等不仅常言 “懜懂”一语, 还习用其叠加式, 既用 “AABB” 重叠式, 如农谚 “懵懵懂 懂, 清明浸种”, 也用 “ $A$ 哩 $A B$ ” 中缀式, 如熟语 “懵哩 買懂, 挑担水桶, 跌泼仂丢掉了一隻, 不晓得轻重”。《汉 语大词典》, 未收两类叠加词。

\section{3. 商补一些词条中的例证}

在《汉语大词典》中, 有的词条例证值得商补, 主要 两方面: 一是例证付阙, 二是溯源例证偏晚。那些例证既 可采于一些辞书, 又可取自其它文献。

\section{1. 词条例证付阙}

【喜】指 “槩, 坛子或缸类”。《篇海类编・器用类》: “甓, 罂属。” [14]《字汇・瓦部》: “彭, 瓶甕。” [15] 《清稗类钞・方言类》: “吴江菜心早上甓。……喑, 坛 也。” [16] (p2236) 晋・谢灵运《初往新安至桐庐口诗》: “景夕群物清, 对玩咸可彭。” 宋 - 沈括《梦溪笔谈》卷 二三: “吴人……作书云: “醋浸曹公一熹……聊备于馔。” ”

方言区如赣语、吴语、客话及中原官话等, 今犹云“瓮”、 “坛子” 或 “缸” 为 “甓” 的。《汉语大词典》释之 “瓮 类陶器”, 未及书证, 当补。

【水色】指 “健康而红润的面色”。“色” 意谓 “脸 上气色”。《说文・色部》：“色, 颜气也。” 2$]$ ( p600) 段玉裁注: “颜者, 两眉之间也。心达于气, 气达于眉间, 是之谓色。” [9]（p431）复合结构 “水色” , 乃谓 “人 的脸部血色”。人们往往把白里透红、健康好看的面色, 称之 “水色好” ; 反之, 则 “水色差” 。如清 - 佚名《情 梦柝》第一回: “当初我随老爷在嘉兴做官, 晓得下路女 子极有水色, 但脚大的多……如今荆小姐, 自然是美的, 只怕那双脚与我的也差不多。”

方言区赣语、湘语、西南官话等, 今仍谓青春、健康 而肤色红润的姑娘为 “水色好”。《汉语大词典》仅释义, 而阙例证。

【筦】本义 “织具” 。《广韵・候韵》: “筦, 织具。” [13]（p352）这种织具是织布机上的一种机件, 其作用是 推拉纬线。《朱子语类》卷八五: “缌十五升, 抽其半, 者, 是一䈐只用一经。” 明 - 宋应星《天工开物 $・$ 乃服》: 


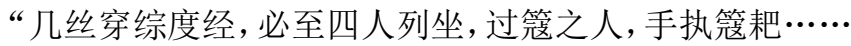
则绦结之。”

二十世纪中叶, 赣省亦产棉。乡间妇女把纺棉织布作 为其主要农活之一。如今已达七、八十岁高龄的农家妇女, 那时几乎都有一手穿针引线、绣花納鞋、纺棉织布的绝佳 手艺, 农家孩子常着家织布。因而, 赣语区人们谓 “管” 如常。此外, 其它方言区如吴语、江淮官话、西南官话等, 亦如此。《汉语大词典》例证阙如。

【筞帚 指“以竹丝等扎成的刷洗锅碗之类的用具”。

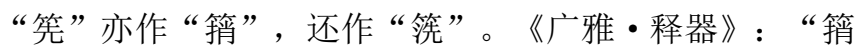
谓之笔。” [6]（p86）清 - 王念孙疏证: “籍, 即今之刷

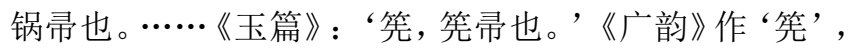
云: ‘䇵帚, 饭具。或作笔。' 是筅与籍异名而同实。” [17]清 - 唐训方《里语征实》: “涤器曰笔帚…凡㕑中洗 釜、瓶等物均用之。” 18$]$ ( p158) 宋・吴自牧《梦粱录・诸 色杂买》: “其巷陌街市, 常有使漆修旧人……并挑担卖 油、卖油苔、扫帚、竹帚、笔帚。”

“笔帚”系通语，广泛通行于南北方言区，如赣语、 吴语、闽语、冀鲁官话等, 皆习用之。《汉语大词典》仅 有释义, 未附例证。

【香几】是指 “一种搁放香炉的几案”。“香” 是一 种用木屑换香料做成的细条, 用以祭祀祖先或神佛, 燃烧 时气味芳香。“几”, 是 “几案”或“搁放物件的小桌子”。

《玉篇・ 几部》: “几, 案也。”[12]复合结构 “香几” 亦即 “搁放香炉的几案”, 殆始于唐宋时代。宋・李昉《太 平广记》卷二九 $O$ : “玉皇授白云先生高骈, 潜使左右置 安道院香几上。”元代以后诸如元杂剧戏曲、明清小说等, 则盛用之。

方言区如江淮官话、吴语、湘语、赣语等, 都有 “香 几”的说法。《汉语大词典》阙其例证。

\section{2. 词条溯源例证偏晚}

【攒劲】 “使劲、用力”义。清・文康《儿女英雄传》 第六回: “他单臂一攒劲, 用力挑开了那棍, 回转身来。” 佚名《施公案》第一一三回: “(谢虎) 一转身直扑庙外 而来, 浑身攒了攒劲, 只听 “嗖” 的一声䠉在墙头, 又一 怱身, 跳在墙外。”

湘语、赣语、江淮官话、西南官话及中原官话等方言 区，人们口语常用之。《汉语大词典》例引 1981 年第 2 期 《人民文学》中的句子 “白天下田攒劲搞生产, 早晚上山 摆弄木耳” 为其始证, 显然时代偏晚。

【烂贱】有一义项为 “极贱或价钱极低”。“烂” 谓 “甚”、“极”义, 言程度高或深。清・吴敬梓《儒林外 史》第三回: “你是个烂忠厚没用的人，所以这些话我不 得不开导你, 免得惹人笑话。” “贱” 本谓 “价钱低”。

《说文・贝部》: “贱, 贾少也。” [2]（p417）段玉裁 注: “贾, 今之价字。” [9]（p282）《六书故・动物四》: “贱, 物贾 (价)之印 (昂) 为贵, 下为贱。” 因而, “烂贱” 意为 “价钱极低”。明・凌蒙初《二刻拍案惊奇》卷二二: “一向家中牢曹什物, 没处藏叠, 半把价钱, 烂贱送掉。”
方言区如粤语、闽语、西南官话等，常用此义。《汉 语大词典》引沈从文《丈夫》中的句子为其始证, 时代过 晚。

【澄】本义 “水清”。《说文・水部》: “㴛, 清也。” [2]（p734）《玉篇・水部》云: “澄同溦。” [12]《方 言》卷十二: “澄, 清也。” [19]（p241）引申为 “让液 体中的杂质沉淀下去, 使其清澈纯净”。《集韵・嶝韵》: “清浊分也。”[10]（p175）即澄而使之清浊分离。《礼 记・坊记》: “醴酒在室, 醍酒在堂, 澄酒在下, 示民不 淫也。”汉・刘安《淮南子・精神》: “肉凝而不食, 酒 澄而不饮, 外束其形, 内总其德, 钳阴阳之和, 而迫性命 之情, 故终身为悲人。”

赣语区人们口语中常用其引申义, 如南昌话 “水浑, 先澄一下”。《汉语大词典》引《三国志》为据, 例证偏 晚。

【苏】本义 “疲倦困乏”。《广韵・薛韵》: “茶, 疲役皃。” [13]（p403）《集韵・薛韵》: “茶, 疲完。” [10（p203）《庄子・齐物论》: “终身役役而不见其成 功, 茶然疲役而不知其所归, 可不哀邪! ”成玄英疏: “茶 然, 疲顿貌也。”

据考察, “茶” 通行于赣语、粤语等方言区。《汉语 大字典》引 《庄子 - 齐物论》为其始证, 《汉语大词典》 引谢灵运《过始宁墅》诗为证, 其例显然偏晚。

【眠梦】意为 “睡梦”。“眠”, “睡”义。《玉篇・目 部》: “眠, 蒋也。” 12$]$ 《正字通・目部》: “眠, 寝 息也，俗谓之睡。”[3] “眠梦” 犹言 “睡梦”。《敦煌 变文集新书》卷二: “昨霄（宵）眠梦有徵祥, 今朝得见 慈悲相。” 唐・李商隐《日高》: “水精眠梦是何人, 栏 药日高红有髣。”

“眠梦” 通行于吴语、赣语、闽语、客话等数个方言 区。《汉语大词典》引许地山《枯杨生花》为证, 其例过 晚。

\section{4. 商补一些词条中的义项}

《汉语大词典》所收词条, 有些是多个义项的, 其中 有的义项未立或失收, 或为词的本义, 或为词的引申义。 而这些未收的义项, 不仅收在其它辞书里, 还时常出现在 人们的日常交流中。例如:

【睩】本义 “谨慎而视”, 实为 “看”、“注视” 义。 《说文・目部》: “睩, 目睐谨也。” [2] (p219) 段玉 裁注: “睩为目睐之谨, 言注视而又谨畏也。” [9] (p134) 《玉篇・目部》: “睩, 视完。” [12]《集韵・烛韵》: “睩, 谨视完。” [10]（p187）其他文献用例, 如《楚 辞・招魂》: “蛾眉曼睩, 目腾光些。”王逸章句: “睩, 视貌也。”又, 《楚辞・悯上》: “哀世兮睩睩, 諓諓兮 嗌喔。”王逸章句: “睩睩, 视貌。”由其本义引申为 “眼 珠转动”。

有些方言区, 人们口语中常用 “眼珠转动” 义。据考 察, 粤语、吴语、赣语、西南官话等方言区, 均有此类用 法。《汉语大词典》 “睩” 条下释 “目明”、“眼睛” 二 义, 未涉 “谨慎而视”, 可补入本义。 
【齐家】“齐家”本谓“治家”。语出《礼记・大学》: “欲治其国者, 先齐其家; 欲齐其家者, 先脩其身。”儒 家把齐家、治国、平天下三者融为一体, 不可或缺, 即先 自治而后治人, 并视之为 “治人” 的根本。

不少方言区如客话、闽语、赣语、平话等, 大多用作 代词, 其与语源无涉, 义即 “大家” 或 “大伙”。《汉语 大词典》收有本义 “治家” , 未涉此义。

【機】本义 “木楔”。《说文・木部》: “樴, 楔也。” [2]（p380）徐锴系传: “機, 谓䙃也, 榍也。此即今俗 以小上大下为樴字。” [20]又, 段玉裁注: “木工于丵枘 相入处, 有不固, 则斫木札楔入固之, 谓之樴。”[9] (p257) 《一切经音义》 “以楔” 注: “今江南言樴。楔, 通语也。” [4] (p1380)

其本义，不少方言区如吴语、粤语、赣语、闽语均习 用; 其引申义 “以木楔硬挤或硬塞进去” , 上述方言区也 常用。还有在其引申义上再引申的, 如赣语 “到后背后面 去站队, 不要樴为取巧不受秩序而硬性插入”。《汉语大词典》 释义未及 “以木楔硬挤或硬塞进去” 这一义项。

【泓】本义 “饮”。《说文・水部》: “㵊, 饮也。” [2]（p749）徐锴系传作 “饮缍也。” [20]段玉裁注: “浴 尸则䁷尸口鼻, 与饮欯义相近。” [9]（p563）清・唐训 方《里语征实》：“饮少曰㵊。” [18]（p74）

方言中有 “小口啜饮” 或 “抿” 义，实用其本义。杨 树达《积微居小学金石论丛四・长沙方言续考》: “今长 沙谓以口饮酒少许为㵊。” 据考察, 吴语、粤语、闽语、 赣语、湘语、徽语、江淮官话及西南官话区, 甚至中原官 话区, 皆习用是语。《汉语大字典》释其本义为 “饮” 。 《汉语大词典》收有 “水深满貌”、“深水” 和 “充满, 遍布”三个义项，未及本义。

【沰】其常用义之一是 “下坠”或 “落下”。《广雅・释 言》: “沰, 硌也。” [6]（p52）王念孙疏证：“磓, 落 也。” [17]《篇・水部》: “沰, 落也, 磓也。” [12] 引申为液体类 “滴落”。《集韵・铎韵》: “沰, 滴也。” [10］（p210）《说文通训定声・需部》: “《周礼 (天官) 掌舍》注作 “涷夢”。今苏俗语如篤, 谓雨声滴沰也。” [21] 液体落下是一滴滴的, 故又转作表示液体或糊状体类 的量词 “滴”。后来, 其量词的范围扩大, 亦可用于液体 以外的物体。

据考察, 吴语、赣语、江淮官话、西南官话、胶辽官 话等方言区都有量词这一用法。如赣语 “一沰饭”、“一 沰鼻涕”、“一沰泥巴” 等。《汉语大词典》 “沰”下仅 收 “红褐色”、“象声词”二义, 未列量词义项。

【派】本义 “水下滴”。《说文・水部》: “溷, 流 下滴也。” 2 2] (p742) 段玉裁注: “今俗谓一滴曰一溷。” [9]（p557）汉 - 王充《论衡 - 自纪》: “德汪濊而渊懿, 知滂沛而盈溢, 笔泷漉而雨集……五吾所谓异也。” 黄晖 《论衡校释》注 “泷漉” 一词云: “《说文》: “泷, 雨 泷泷也。溷, 流下滴也。”方言》: “泷溷谓之沾渍。” 泷溷、泷漉语之转。”

方言区如西南官话、客家话、吴语、赣语等, 常用此 义。《汉语大词典》除列 “扣击”、“水名” 二义外, 未 立 “水下滴”这一义项。
【当昼】 “当”古语有 “中”或 “中正”义。《集韵・宕 韵》：“当, 中也。” [10]（p172）“昼” 除了“白天” 义外, 还指 “中午时分”。《玉篇・书部》: “昼, 日正 中。” [12]《孟子・滕文公上》: “民事不可缓也。诗云:

“昼尔于茅, 宵尔索绹; 亟其乘屋, 其始播百谷。” ”孙 画疏: “日中也。”故 “当昼” 谓 “中午” 或 “正午”。 唐・韩愈《庭楸》诗: “当昼日在上, 我在中央间。”

明・黄宗羲《古倝乡音集证》: “俗读当午为当昼。” [22］（p1881）又, 《越言释》: “越人以午为昼。” [23] “中午” 或 “正午” 谓之 “当昼”, 尤其是盛夏烈日当空 的 “中午时分” , 今方言区如吴语、赣语、闽语、客话、 徽语等, 均有此说。《汉语大词典》收有 “白天”一义, 未及 “中午” 或 “正午” 这一常见义。

【造馟这个词应有两个义项: 一是佛教语“做坏事”; 二是 “可怜”。义项二中的 “造” 通 “遭”, 意即 “遭受” 义。《说文通训定声》: “造, 叚借为遭。《书・大诰》: “予造天役。’马注: “遗也。”按: 遗者, 遭之误字。” [21]如《庄子・大宗室》: “造适不及笑, 献笑不及排。” 于省吾新证: “造应读作遭。” 因此, “造䔣” 则谓之 “遭 受他物所造之罪”, 故而又转引为 “可怜” 义。《红楼梦》 第九四回: “若是为着一两个不好, 个个都押着他们还俗, 那又太造䕉了。”

赣语两个义项均用; 湘语、客话及西南官话等方言 区, 多用后一义项。辞书如《当代汉语词典》、《现代 汉语大词典》等均收方言 “可怜” 义, 而《汉语大词典》 未列此义。

此外, 还有一些词条的意义需要进一步辩证, 即使 义同的其语用义也有细微差异。如 “捡拾”一词, 《汉 语大词典》除列有 “搜集”、“拾取” 二义外，未曾立 “收拾”、“整理” 两个义项, 而此在西南官话、客话、 赣语、湘语等方言区是常用的, 与前者的意义也是有些 差别的。还有一些词条释义, 《汉语大词典》存有明显 多误, 如 “牯” 释之 “母牛”, “五精” 谓之 “五方之 星”, “蒜钵子” 言之 “方言, 大蒜的根” 等。对此, 学者已有论述, 兹不赘述。

\section{5. 结束语}

总而言之, 类似的问题在《汉语大词典》中还有不少, 在此难于一一。冊庸讳言, 《汉语大词典》确实存有一定 的瑕疪, 但瑕不掩瑜, 这无损于它的耀眼光辉。的确, 任 何辞书不论其如何精雕细刻, 均有可能出现一些令人扼腕 的地方, 因此修订工作必不可少, 《汉语大词典》无疑也 不例外。我们深信, 在以后的编修工作中, 只要编者怀有 “闻过则喜” 的海涵胸襟, 读者抱有精诚匡误的担当责任, 共同为着一个目标, 通力合作, 不断地剔除瑕疪, 不停地 追求完美, 最终是会把《汉语大词典》铸造成中国辞书史 上的尧楚之作。正如徐时仪先生所说的：辞书的修订 “是 一个逐渐完善与时俱进的大工程”, “一次修订一个飞跃, 一次修订一个台阶”, “一本辞书只有经过 “老君炉炼丹” 般的不断修订才有可能成为精品之典。”[24]（p1-6） 


\section{致谢}

本文为中国国家社会科学基金后期资助项目《赣方言 古语词探源与论析》（批准号14FYY027）和江西省社科联 规划重点项目《赣鄱方言与赣鄱文化研究》(批准号13YY01) 的阶段性成果之一。

\section{参考文献}

[1] 虞万里. 《汉语大词典》编纂琐回忆 [J]. 辞书研究, 2012, (2)。

[2]［汉]许慎. 说文解字 [M]. 北京: 中华书局，2002。

[3]［明]张自烈. 正字通 $[\mathrm{M}]$. 清康熙刻本。

[4] [唐]玄应、惠琳等撰, 徐时仪校注. 《一切经音义》 [M]. 上海：上海古籍出版社，2008。

[5]［清]桂馥. 札朴 [M]. 北京：中华书局，1992。

[6] [魏]张揖. 广雅 $[\mathrm{M}]$. 北京: 中华书局, 1985。

［7］［汉］佚名撰, [晋]郭璞注. 尔雅 [M]. 北京: 中华书局, 1985。

[8］ [清]郝懿行. 尔雅义疏 $[M]$. 上海: 上海古籍出版社, 1989。

[9] [清]段玉裁. 说文解字注 [M]. 杭州: 浙江古籍出版社, 2002 。
[10］［宋］丁度. 宋刻集韵 [M]. 北京：中华书局，2005。

[11］［清］章炳麟. 新方言 $[M]$. 上海：民国上海右文社排印本。

[12］［南朝・梁］顾野王. 玉篇 $[M]$. 丛书集成初编 - 语文学类。

[13] [宋]陈彭年. 钜宋广韵 $[M]$. 上海: 上海古籍出版社, 1983。

[14］［明］宋濂. 篇海类编 [M]. 明刻本影印。

[15］［明］梅膺祚《字汇》，清康熙二十七年灵隐寺刻本。

[16］［清］徐珂. 清稗类钞 [M]. 北京：中华书局，1986。

[17］[清]王念孙. 广雅疏证 [M]. 四部备要・经部小学。

[18］［清］唐训方. 里语征实 [M]. 扬州：广陵书社, 2003。

[19］［汉］扬雄撰, [晋] 郭璞注. 方言 [M]. 北京: 中华书局, 1985。

[20］ [南唐]徐锴. 说文解字系传 $[M]$. [清] 乾隆四十七刊本。

[21］清］朱骏声. 说文通训定声 [M]. 临啸阁藏版。

[22] 许宝华 宫田一郎. 汉语方言大词典 [M]. 北京: 中华书局, 1991 。

[23］[清]茹敦和. 越言释 $[M]$. [清]道光葛氏啸园藏本。

[24] 徐时仪. 《朱子语类》词汇研究与《汉语大词典》修订 $[J]$. 陇东学院学报, 2013, Vol.24（4）。 